\title{
THE BOROUGH POLYTECHNIC, LONDON
}

\section{NEW EXTENSION BUILDING}

$\mathrm{T}$ HE new extension to The Borough Polytechnic, which has been erected by the London County Council at a cost of nearly a quarter of a million pounds, marks a further stage in the post-war provision for higher technological education in the London area. The Borough, like other London Polytechnics, came into being towards the end of the past century, receiving endowments and financial aid made available as the result of legislation consolidating certain London charities-the City of London Parochial Charities Act (1883).

The Polytechnics are distinct from the technical colleges owned by the London County Council in that they possess their own legal identities with their own governing bodies and enjoy a considerable measure of autonomy. They have, however, for many years received grants from the London County Council, which is represented on the boards of governors.

Prior to 1939 several of the Polytechnics had affiliated trade schools; but under the Education Act of 1944 these have become independent secondary technical or modern schools, and more and more the Polytechnics have assumed a characteristic pattern catering primarily for full-time or part-time students of seventeen years or older who wish to follow courses leading to degrees of the University of London or to diplomas or certificates in various technologies. There has been a general tendency for a stratification of technical and higher technological education and, while some subjects are taught in all the Polytechnies, each institution has adopted certain fields as its own.

Thus The Borough Polytechnic, apart from its general courses in science and engineering, has, since its establishment in 1891, often taken the initiative in meeting the special needs of an industry and in more than one case has followed the dictum of the American educationist that a technological institute "must lead industry; it must reflect the future rather than mirror the past". The Polytechnic has provided pioneer courses in such subjects as bakery (1894), paints (1892), oils and fats (1893), plastics (1930), chocolate and sugar confectionery (1947), pulse techniques (1951), pest control (1952) and applied nuclear physies (1952). In 1948 the National College of Heating and Ventilation, Refrigeration and Fan Engineering was established under the directorship of Dr. D. H. Ingall, the principal of the Polytechnic. This, like other similar 'national colleges', receives direct grants from the Ministry of Education. Various departments or sections of the Polytechnic have a de facto or de jure regional or national status in that they attract students from a wide area.

The science work of the Polytechnic began at an early date, and students gained B.Sc. degrees of the University of London as early as 1903. The Chemistry Department of the Polytechnic was established in 1897 under the direction of F. Mollwo Perkin; he was followed by C. Doree (1909) and H. Lambourne (1924) and then by Dr. E. C. Pickering (1926), who retires this year after seeing his Department reestablished in the new extension.
The new building includes four floors, with lecture rooms and laboratories for different branches of chemistry and for botany, zoology and biochemistry. From each of the 'academic' sections of the science department branch off various 'applied' lines of activity, some of which have been identified with the Polytechnic for long periods.

In the field of applied chemistry, facilities (including pilot-plant equipment) are available for plastics; paints, varnishes and pigments ; oils, fats, waxes, soaps and detergents; and for dental mechanics. In applied biology special provision is made for microbiology and hygiene, and for entomology and pest control. The food science and technology section includes laboratories for food analysis and for cereal testing-with a collection of instruments for the measurement of the physical properties of cereal products rarely seen outside the research laboratories of a few of the larger firms. Extensive provision is made for instruction in bakery subjects and for chocolate and sugar confectionery.

Since 1945 a number of postgraduate and other specialized courses sponsored by the Regional Council for Higher Technological Education have been arranged at the Polytechnic in such subjects as synthetic detergents - to meet the needs of a rapidly growing industry-and in food biochemistry and human nutrition, the lecturers being drawn from the university medical schools and from research institutes.

Such courses as these, on subjects normally available only to limited groups of full-time university students (and sometimes not available at all in the universities), are an essential part of the work of a modern Polytechnic; they aim at meeting the needs indicated by the members of so many production teams who have visited the United States and have pleaded on their return for an extension of the training facilities for scientific workers and technologists in industry. The Polytechnic has been fortunate in securing the co-operation of university lecturers and other scientific workers in research institutes, in industry or in private consultant practice, who to an increasing extent have shown their willingness to direct these specialized courses.

It is part of the policy of the Ministry of Education and of the London County Council to encourage research in the Polytechnics, and the new extension at The Borough includes research laboratories for organic chemistry and biochemistry; postgraduate students and also members of the teaching staff are working for higher degrees of the University of London or for the fellowship of the Royal Institute of Chemistry.

The Ministry of Education has made arrangements with the Commissioners of Inland Revenue, whereby industry may claim tax relief on grants to Polytechnics. The Borough Polytechnic has benefited from this new approach and acknowledges the assistance received from various sections of industry. These recent gifts follow an earlier pattern and justify the optimism of Sidney Webb (in his introduction to a volume published in 1910 to record the origin and growth of the Polytechnic): "how little 
there is of truth in the statement that the grant of public money necessarily dries up the sources of private benevolence".

In the same article, Webb recorded his conviction "of the great advantage that the Borough Poly. technic has derived from its independence in administration, and its freedom to start new experiments", and expressed the prophetic view that "it is one of the special problems in Democracy which make the twentieth century so interesting to discover how we can most successfully fit the voluntary agency in the government framework so as to secure the maximum advantages of both".

The Governing Body of The Borough Polytechnic has provided a field for voluntary endeavour on the part of many distinguished men and women, and in this number must be placed Mr. D. C. Highton, who, on his retirement last month from the chairmanship (following more than twenty-five years service in this capacity), can see in the new extension the results of his endeavours and the beginning of a new phase in the history of The Borough Polytechnic.

Francis Aytward

\section{LUMINESCENCE OF INORGANIC PHOSPHORS}

A CONFERENCE on luminescence with specific reference to inorganic phosphors was held in the Cavendish Laboratory, Cambridge, during April 7-10, being organized by the Electronics Group of the Institute of Physics. This was the first largescale conference in Europe on the subject since the Faraday Society conference in Oxford in 1938 and was attended by many visitors from Europe, India, Canada and the United States. Proceedings were arranged to give ample time for discussion by previous circulation of preprints of papers which were read in précis form.

An opening lecture by Dr. S. T. Henderson (Thorn Electrical Industries, Enfield) reviewed the advances in luminescence since 1938 with particular reference to the commercial developments of fluorescent lighting and electroluminescence and to the extensive progress in fundamental research on phosphor constitution and mechanisms of luminescence. This was followed by a demonstration lecture given by $\mathrm{Dr}$. J. W. Strange (Thorn Electrical Industries, Enfield) on some unsolved problems in luminescence, such as sensitization of luminescence, infra-red response of phosphors and the complexities of thermal glow phenomena.

The main proceedings fell into three daily sessions, the first being devoted to phosphors involved in commercial applications. The opening paper, by Mr. C. G. A. Hill (Levy-West Laboratories, Wembley), reviewed developments in cathodoluminescence with special reference to applications such as calciummagnesium silicates for 'flying-spot' tubes and the zinc-magnesium fluorides with $1 / 10$ sec. exponential decay for radar screens. As indicated by this and a later paper, some phosphor efficiencies for cathoderay excitation are nearing the maximum possible values.

There followed a series of four papers on phosphates and other phosphors of particular interest for fluorescent lamp application. The first, by Miss M. Doherty and Mr. W. Harrison (Siemens Lamp
Research Laboratories, Preston), was concerned with phosphor synthesis, chromaticity and ageing of fluorescent coatings. In the latter case, improvement on 1946 performance due to the use of the halophosphate phosphors was very evident. The second of these papers, by Dr. P. W. Ranby, Mr. D. H. Mash and Dr. S. T. Henderson (Thorn Electrical Industries, Enfield), considered the alkaline earth pyrophosphates in some detail, with special reference to the relations between phosphor characteristics and crystal structure. The third paper, by Mr. A. H. McKeag and Mr. E. G. Steward (General Electric Research Laboratories, Wembley), also stressed the structural aspects of phosphate and of silicate phosphors in relation to their luminescence characteristics. A short paper by Dr. S. Rothschild described some unusual phosphors, notably boron phosphate, alkaline earth vanadates and some arsenatoapatites.

The second half of the session was given up to a number of papers on electroluminescence. The continuous excitation of luminescence by application of an alternating electric field to a phosphor was reported by Prof. G. Destriau (Paris) at the Oxford conference in 1938. He presented a paper in the present proceedings on the brightness wave-forms of electroluminescence. During recent years, electroluminescent phosphor plaques as large-area light sources have been developed commercially. Dr. K. H. Butler and Dr. J. F. Waymouth (Sylvania Electrical Products, Salem, United States) gave a paper mainly concerned with the production and characteristics of phosphors used in these electroluminescent lamps. Another paper, by Prof. A. Luyckx (Louvain) and Mlle. A. J. Stokkink (Charleroi), described brightness/applied voltage characteristics for conventional phosphors. An out. standing paper of this group was that of Dr. W. W. Piper and Dr. F. E. Williams (General Electric Co., Schenectady, United States), providing a theory of electroluminescence in terms of a Schottky exhaustion barrier model for the phosphor-electrode boundaries. Discussion on this paper included a notable contribution of a modified theory by Dr. G. F. Alfrey and Mr. J. B. Taylor (University of Birmingham), which took into account electrons thermally excited from trapping-states. This theory correlated well with experiment, particularly with reference to the complex temperature variation of electroluminescence. Two short papers concluded the session, one on electroluminescence in organic adsorbates by Prof. A. Bernanose (Nancy) and one on electroluminescence in silicon carbide crystals by Dr. G. Szigeti (Budapest). From the papers and discussions it was evident that electroluminescence research is attracting much attention from both industrial and academic laboratories.

The second session focused attention on the physical chemistry of phosphors and attempts to determine their detailed constitution by physical measurements. The opening paper, by Dr. F. A. Kröger (Philips Research Laboratories, Eindhoven), gave an up-to-date review of the physico-chemical approach made by his laboratories and of the theory of activation of sulphides in terms of lattice vacancies and valence compensation. Discussion on this paper included a consideration of the function of ' $k$ iller' impurities, of the spatial relations between co-activator ions in the sulphides and of the possibility of applying paramagnetic resonance techniques to determine the state of impurity ions in the matrix crystal lattice. The second paper, by Dr. J. H. Schulman (Naval 